\title{
A NOÇÃO DE PRÉ-CONSTRUÍDO E SEUS DESDOBRAMENTOS NO PROCESSO CRIATIVO DO DISCURSO PUBLICITÁRIO
}

\author{
Fábio Hansen
}

\begin{abstract}
RESUMO: Cette étude explore le processus créatif de la publicité dans une perspective discursive, convergeant vers une réflexion sur la présence de l'autre comme constitutive de la construction du sens dans ce processus. La thèse soutenue ici, à partir de l'observation de ce fonctionnement discursif, c'est que l'autre s'y introduit sous la forme de préconstruit et cela est attesté à travers la mémoire discursive. À partir de l'analyse du discours publicitaire, nous avons constaté que son processus de production est moulé sur chacun des différents moments discursifs de ce processus et chacun y fonctionne en tant que préconstruit par rapport à l'autre, reliant préconstruits et construits.
\end{abstract}

PALAVRAS-CHAVE: discurso publicitário, processo criativo, pré-construído.

Estudos do campo da Comunicação têm desenvolvido, frequentemente, avaliações críticas dos processos de produção, circulação e consumo dos sentidos em produtos culturais ou eventos comunicacionais. Entretanto, as análises costumam recair sobre os produtos, deixando o processo em um plano secundário. $\mathrm{O}$ nosso propósito, porém, não são as peças publicitárias, mas sim o seu processo de constituição. Consideramos ser mais rico estudá-lo, em detrimento ao seu produto, na relação visível e (in)visível. O deslocamento proposto possibilita que se pense o processo de produção da linguagem e não somente seus produtos.

Neste estudo apresentamos um novo olhar sobre o processo criativo publicitário. À medida que estamos vinculando-o à Análise de Discurso - onde encontramos acolhida e um espaço de resistência -, almejamos examinar como funciona a heterogeneidade no processo criativo do discurso publicitário, além do funcionamento do seu processo de construção e dos mecanismos de produção dos sentidos.

Nosso objeto de estudo é o processo criativo do discurso publicitário, com o objetivo de realizarmos uma reflexão sobre o outro constitutivo deste processo (re)conhecendo de que modo irrompem os pré-construídos que atravessam o discurso publicitário - e verificarmos como se dá esse atravessamento, pelo viés da memória discursiva.

A memória discursiva, pensada por Orlandi (2001, p.31) é "o saber discursivo que torna possível todo dizer e que retorna sob a forma do pré-construído, o já-dito que está na base do dizível, sustentando cada tomada da palavra”. A memória é o já-dito, os

\footnotetext{
Doutor pelo Programa de Pós-Graduação em Letras da Universidade Federal do Rio Grande do Sul (Ufrgs). Professor na Escola Superior de Propaganda e Marketing (ESPM/RS) e na Universidade de Santa Cruz do Sul (Unisc).
} 
sentidos a que já não temos mais acesso, que foram constituídos ao longo de uma história e que estão em nós, sem pedir licença.

Além destas questões, analisamos a relação do discurso publicitário com a exterioridade, examinando como comporta elementos provenientes do exterior. Em síntese, o eixo central da nossa proposta é questionar a presença do outro no processo criativo do discurso publicitário, ou seja, como o outro se atravessa no processo criativo do discurso publicitário?

Para tanto, acompanhamos e analisamos um processo criativo real em uma agência de propaganda da cidade de Porto Alegre. Reforçamos, conforme já antecipado, que o foco será dado à análise dos processos de produção, não dos produtos, ou seja, não serão analisados os anúncios publicitários, e, sim, o processo de sua criação. Em suma, o intento foi examinar todo o processo criativo por meio dos diálogos internos da criação. As sequências discursivas (SDs) que compõem o corpus discursivo foram produzidas em situações experimentais, como a observação não-participante do brainstorm e dos próprios publicitários (dupla de criação) envolvidos, além de documentos como briefing e rafe fornecidos e liberados pela agência de propaganda. As sequências discursivas oriundas da observação não-participante durante o brainstorm foram originadas com base nas transcrições do material coletado em áudio e são, sobretudo, orais. Por sua vez, as sequências discursivas materializadas no briefing e no rafe são de ordem escrita. Organizamos a natureza do corpus (experimental) em materiais escritos (briefing e rafe) e materiais sonoros (brainstorm).

A partir do nosso corpus, evidenciamos que o discurso-outro é mobilizado e chamado a intervir sob a forma de pré-construído. Para tanto, elencamos préconstruídos recuperados e que remetem, de acordo com Orlandi (2001), o dizer imediatamente a uma formação discursiva (FD) e, logo, a uma formação ideológica (e não outra) dominante naquela conjuntura.

Atestamos que o discurso-outro emerge via pré-construído, produzindo efeitos de sentido. O pré-construído é um elemento do interdiscurso que, por sua vez, é o espaço externo onde são localizados e acionados outros discursos em circulação, constitutivos da FD. O interdiscurso se apresenta oculto, mas a partir de um determinado recorte, se lineariza no intradiscurso. Esclarecemos, então, que o nosso trabalho de interpretação, enquanto analistas do processo criativo no discurso publicitário (nosso objeto de estudo), ocorre, sobretudo, no espaço que vai da constituição dos sentidos (o interdiscurso) à sua formulação (o intradiscurso), por meio da identificação dos elementos do pré-construídos.

$\mathrm{Na}$ análise do processo criativo do discurso publicitário o sujeito se movimenta entre o interdiscurso e o intradiscurso, identificando-se de modo inconsciente e determinado sócio-histórico e ideologicamente com saberes da ordem interdiscursiva. Nessa movimentação do sujeito reconhecemos dois momentos discursivos principais (figura 1), a saber: o briefing e o brainstorm. 


\author{
Briefing \\ Momento discursivo 1

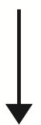 \\ Brainstorm \\ Momento discursivo 2
}

Figura 1 - momentos discursivos do processo criativo do discurso publicitário.

O briefing, primeiro dos momentos discursivos, reúne informações preliminares com todas as instruções que o anunciante fornece à agência para orientar seu trabalho. É uma fase completa de estudos e de coletar informações a respeito do produto, do mercado, do consumidor, da empresa e dos objetivos do anunciante. Briefing vem do inglês, do verbo to brief que significa resumir, fazer a apresentação sumariada de alguma coisa (BERTOMEU, 2002). Funciona como um elo entre o publicitário profissional de atendimento e os criativos, traduzindo o discurso do marketing para o discurso da criação. Materializa a palavra do anunciante.

Já o brainstorm, segundo momento discursivo, é uma sessão de troca e criação de ideias para debater e pesquisar alguma nova ideia. São agitações cerebrais em grupo, explosões, tempestades de ideias, um estado criativo, do qual resultam esboços de ideias que são rascunhadas. $\mathrm{O}$ nosso objeto de estudo se centra neste momento discursivo e nos criativos (dupla de criação - diretor de arte e redator), pois o processo criativo tem como auge o brainstorm, embora seja impossível deixar de fazer referência aos demais momentos e participantes envolvidos. No momento posterior ao brainstorm há a análise das melhores ideias e a seleção daquela que será apresentada ao anunciante pelo profissional de atendimento.

O atendimento, na criação de uma peça (ou campanha) publicitária, trafega entre anunciante e agência, mais precisamente entre anunciante e criativos (vide figura 2). Após a elaboração do briefing (passo 1), o atendimento repassa-o aos criativos da agência. Estes, por conseguinte, criam, em um brainstorm (passo 2), as ideias para as peças publicitárias que são discutidas primeiro com o diretor de criação antes de serem levadas, em forma de rafe (passo 3) ao atendimento. Este último, por sua vez, apresenta o layout da ideia criativa (passo 4) ao anunciante, para ser aprovada integralmente, em partes ou reprovada (passo 5). Em caso de aprovação parcial, as impressões do anunciante e as alterações decorrentes são encaminhadas pelo atendimento à criação, que as executa e aguarda nova apresentação ao anunciante, até a aprovação final. 


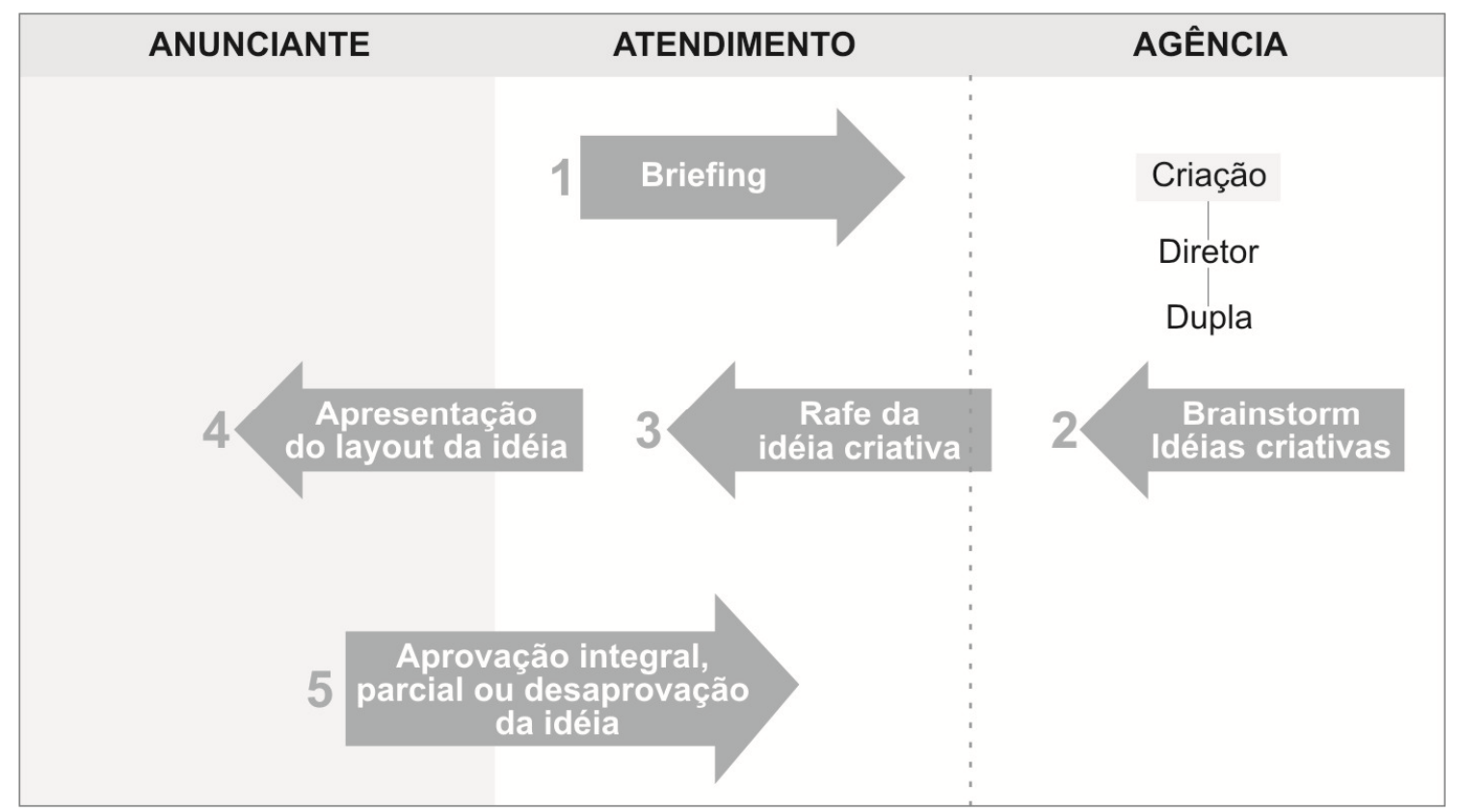

Figura 2 - O fluxo do processo criativo do discurso publicitário.

Tal figura evidencia que o processo criativo é a articulação de todos os momentos discursivos que levam a um anúncio publicitário. O processo criativo não está apenas no momento discursivo número dois - o brainstorm -, até porque ele depende do que veio antes, no momento discursivo número um - o briefing -, e produz algo que irá para além, para o terceiro momento discursivo - o rafe -, com os primeiros esboços da peça publicitária, em anotações e rascunhos. Nesse trajeto, o sentido está em movimento, entre um momento e outro, deslizando.

Em cada um dos dois momentos discursivos (briefing e brainstorm) aqui selecionados para análise, verificamos processos significativos que trazem no interior a presença do outro. Pelo papel do interdiscurso no intradiscurso e a apreensão do interdiscurso como corpo de traços formado na memória discursiva (PÊCHEUX, 1997), identificamos o atravessamento do outro no processo criativo do discurso publicitário. Percebemos como os campos discursivos movimentados ressoam desde o interdiscurso e quais relações estabelecem com a memória discursiva. Em outras palavras, consideramos significativa a presença do outro. Para tanto, a noção teórica de préconstruído é indispensável.

Foi Paul Henry (1993) quem propôs o termo "pré-construído" para dar conta da presença do outro e a fim de designar o que remete a uma construção anterior e exterior ao discurso do sujeito. O pré-construído é algo que fala sempre antes, em outro lugar e independentemente, determinado materialmente no interdiscurso. Em outros termos, o pré-construído é um elemento do interdiscurso re-inscrito no (intra)discurso do sujeito e caracteriza-se, pois, por ser proveniente da exterioridade, proveniência esta que é esquecida.

Deslocando a noção de pré-construído, diríamos que no processo de criação do discurso publicitário elementos pré-construídos produzidos no primeiro momento 
discursivo (briefing) são acolhidos, absorvidos, reconfigurados, reformulados e apagados durante o segundo momento discursivo (brainstorm).

À luz da Análise do Discurso, são os objetos do discurso publicitário que ficam registrados no briefing. É neste documento, confeccionado pelo publicitário encarregado do atendimento ao anunciante, que a dupla de criação (redator e diretor de arte) tomará conhecimento não só de quem é o anunciante, mas daquilo que ele quer dizer ao seu público-alvo. Por conseguinte, é pelo briefing que o criativo alimentará o seu brainstorm. Sustentada pelas informações compiladas neste documento a dupla de criação reunirá condições de iniciar o seu momento particular de criação, pois o processo criativo como um todo já teve início muito antes, quando do contato direto entre o anunciante e atendimento, indispensável à construção do briefing.

$\mathrm{O}$ atendimento traduz para a dupla de criação, na forma de um briefing, o que foi discutido e decidido na conversa com o anunciante. A partir dessa tradução, via briefing, concebe-se a formação do pré-construído para o brainstorm, fornecendo os objetos do discurso. Desse modo, adiantamos que o "outro" encontrado nos diálogos internos do processo de criação é entendido por nós como um pré-construído. A partir disso, propomos que o briefing seja entendido como pré-construído do brainstorm, porque o construído de um (do briefing) é pré-construído do outro (do brainstorm). $\mathrm{O}$ primeiro alimenta o segundo, um traduz para o outro o que acontece anteriormente. $\mathrm{O}$ brainstorm incorpora elementos pré-construídos produzidos no briefing, mas que mesmo lá, já fazem parte dele. Talvez caiba dizer que o discurso-outro "sai" de lá (do briefing) como construído, mas emerge como pré-construído (no brainstorm), como um recorte a ser linearizado no intradiscurso.

Outrossim, é preciso salientar que a teoria propõe o pré-construído como um efeito de anterioridade que e só é passível de ser considerado pré-construído discursivo enquanto eco daquilo que chega como determinação. Aplicando esta noção à prática do processo criativo do discurso publicitário, diríamos que o briefing que aparece no brainstorm como determinante dele, se relaciona com o briefing original, porém só se relaciona, pois não é mais o briefing real, mas sim o briefing interpretado pelos criativos, uma vez que já passou pelo gesto de interpretação. Por esse motivo, afirmamos que no brainstorm cria-se "um certo" briefing. Não é o próprio briefing, ou seja, é a interpretação do briefing que aparece na forma de um pré-construído. É um efeito de briefing, é um efeito do pré-construído.

Resumindo, o briefing chega ao brainstorm como um efeito daquilo que estava antes, mas não exatamente igual àquilo que estava antes. Ato contínuo, no processo criativo há um efeito de pré-construído (efeito de "sempre-já-lá"). Sempre que tratarmos do momento discursivo anterior que é pré-construído do próximo momento discursivo, estaremos tratando do efeito. Isso se presta para amenizarmos uma possível linearidade, como se fosse uma reação em cadeia, entre o que vem como resultante e o que aparece como uma filiação apontando para sua origem. O efeito é vinculado a etapa anterior, mas não é exatamente o que chega na etapa posterior.

O processo criativo do discurso publicitário vem sobrecarregado de exigências: os objetivos almejados pelo anunciante, o prazo para a criação, a verba disponível, os concorrentes, o produto a ser anunciado, o veículo de comunicação em que a peça publicitária circulará, isto é, determinações que endossam a heterogeneidade do discurso publicitário. Todos esses elementos dão as condições de produção do discurso publicitário e se constituem nos pré-construídos da criação. Assim, o briefing, ao documentar estas informações indispensáveis ao processo criativo, pré-constrói o 
mecanismo discursivo no processo criativo. Vale dizer, na perspectiva discursiva, que o construído do briefing redefine-se como pré-construído dos criativos no brainstorm. De fato, alguns dos elementos pré-construídos do brainstorm surgem como construído no briefing.

As sequências discursivas (SDs) 1 e 2 (a seguir) confirmam que o construído (a verba e o prazo disponíveis) do briefing - o primeiro momento discursivo do processo criativo -, redefine-se como pré-construído do brainstorm - o segundo momento criativo. Podemos acrescentar, de imediato, que um momento discursivo reinscreve-se em cima do outro momento discursivo, ou seja, o que é trabalhado no brainstorm já vem do momento discursivo anterior, o briefing, uma vez que a dupla de criação não cria sem um briefing, bem como um briefing inexistiria sem o profissional de atendimento e assim por diante.

SD1 - custo de produção e demanda de tempo.

SD2 - nem todas as ideias a gente vai conseguir executar de forma barata e rápida.

Outra demonstração de que o briefing, enquanto pré-construído, determina o discurso dos criativos tanto quanto o interdiscurso está na necessidade de dizer, se dá pelas sequências discursivas 3 e 4 , pinçadas justamente durante o brainstorm, em um diálogo entre a dupla de criação.

SD3 - caminhão de mudança, o motorista com viseira, protetor solar e óculos de sol, como se estivesse indo para praia.

SD4 - fazer gráficos como se fossem prédios para falar em crescimento.

Na SD3 o diretor de arte propõe uma ideia ao redator, sugerindo elementos que remetessem a Florianópolis, cidade para onde a empresa do anunciante estava ampliando as suas operações. Os elementos (viseira, protetor solar, óculos de sol, praia) listados pelo diretor de arte que sugerem um ambiente de praia, como Florianópolis, são pré-construídos, bem como os prédios referenciados na SD4. Os prédios não são uma escolha ao acaso. Eles se justificam à medida que o anunciante é do ramo imobiliário. Estas informações (anunciante do ramo imobiliário estendendo suas operações a Florianópolis) foram materializadas no briefing, Nesse sentido, há a comprovação de que uma etapa de produção (o brainstorm) é determinada pela anterior (o briefing).

O redator, por sua vez, na SD5, alerta o diretor de arte para o fato de que o caminhão de mudança (SD3) poderia provocar um deslizamento de sentido, sugerindo que a empresa não estivesse em um estágio de crescimento, com a expansão de suas unidades ao estado vizinho, mas sim estivesse literalmente de mudança para Santa Catarina, despedindo-se do Rio Grande do Sul. Esse detalhe na ideia exposta pelo diretor de arte romperia com um construído do briefing que passou a ser um préconstruído no brainstorm.

SD5 - cuidado para não dizer que está saindo daqui, pois não está.

Essa preocupação dos criativos em não romper com o sentido dominante no processo de criação do discurso publicitário foi determinada por um construído do briefing e, por extensão, um pré-construído do brainstorm. Como o criativo é atravessado por discursos muito específicos e pré-construídos muitos distintos, estejam eles linearizados no briefing ou dispersos no interdiscurso, a incorporação dos préconstruídos é determinada pela FD que, por sua vez, determina-o.

Outras sequências discursivas reveladoras da condição do briefing como préconstruído do brainstorm são as de número 6 e 7. Na SD6 a dupla de criação se dá conta 
de que a ideia pensada não atenderia uma das premissas (credibilidade) expostas pelo atendimento no briefing e recuperada na SD7. Como a preocupação latente no briefing era pautar o ingresso do anunciante do ramo imobiliário no mercado catarinense pela oferta de profissionalização e consequente credibilidade, esse sentido deveria ser mantido nas ideias propostas pelos criativos durante o brainstorm. Por essa razão, certificamo-nos de que constituem o pré-construído os sentidos pré-existentes, responsáveis por sustentar o atual sentido, fazendo com que o publicitário busque fora aquilo que estará dentro, aquilo que será inserido no discurso, corroborando, assim, que o pré-construído inscreve a exterioridade no discurso.

SD6 - um avião de papel não passa credibilidade.

SD7 - marcar a sua chegada de forma profissional e passando credibilidade.

Muitos dos pré-construídos linearizados, como o avião de papel (SD6), o caminhão de mudança (SD3), a pipa (SD8) são elementos que se movimentam (assim como o anunciante estava em movimento em direção a Santa Catarina). Inferimos que as ideias criativas da pipa, do avião de papel e caminhão de mudança, mesmo que produzissem um mesmo sentido, provavelmente foram descartadas porque o avião de papel não passaria credibilidade, conforme confirmam os publicitários nas SD6; talvez porque a pipa com frequência não chega ao destino, contida pelos obstáculos do caminho (ficando presa a fios elétricos, por exemplo). Mesmo outra ideia (SD9), poderia induzir ao sentido de migração, assemelhando-se ao significado impetrado no caminhão de mudança, ou seja, mudar (algo que não convinha por não ser isto que deveria ser anunciado). Em síntese, os pré-construídos que se desviam do sentido são escanteados, permanecendo apenas aqueles que sustentam o atual sentido.

SD8 - imagem de um menino dando mais corda numa pipa.

SD9 - pássaros migrando.

O que de fato importa na perspectiva discursiva é esse alinhamento que articula pré-construído a construído. Vale dizer que cada momento discursivo do processo em tela é um pré-construído que no momento discursivo subsequente inscreve-se como construído. Ou seja, cada momento determina o subsequente. Os elementos do briefing, enquanto pré-construído, são re-inscritos no brainstorm e o constituem.

Se por um lado, o atendimento traz, por intermédio do briefing, pré-construídos sobre os quais a dupla de criação trabalha durante o brainstorm, por outro lado, igualmente irrompem pré-construídos introduzidos pelos próprios criativos. São os elementos discursivos fornecidos pelo interdiscurso e incorporados ao brainstorm. Assim, o discurso-outro não fica restrito aos pré-construídos do briefing.

Ao atestarmos que os criativos recorrem ao interdiscurso, estamos nos reportando ao discurso-outro, a tudo que está disperso no horizonte, mas que só tem materialidade via pré-construído. É por essa razão que do interdiscurso irrompe o préconstruído, uma vez que o interdiscurso é o seu lugar de constituição.

Ao identificarmos elementos do pré-construído no intradiscurso é possível se "enxergar" o interdiscurso e é deste modo que se faz a passagem, na Análise do Discurso, do interdiscurso para o intradiscurso. O interdiscurso aparece na forma de pré-construído e só assim se pode "visualizá-lo". Não há outra maneira de "vê-lo" no intradiscurso, haja vista que ele é uma abstração, um conjunto intangível. E no processo criativo do discurso publicitário, enquanto evento discursivo, ele irrompe na forma de 
pré-construído e a abstração se torna visível no intradiscurso, onde o pré-construído passa a ter materialidade.

Diante disso, destacamos um aspecto relevante do processo de criação: os criativos, no brainstorm, não trabalham apenas com os elementos discursivos do briefing. Outros saberes e vozes, além daqueles já sabidos e organizados no briefing, participam do brainstorm. Em um primeiro momento, o criativo se concentra nos construídos do briefing para determinar o que mobilizará da memória do dizer. Em seguida, referências provenientes do interdiscurso surgirão ao manusear com saberes sócio-históricos disponíveis para o sujeito, concebidos como pré-construídos. Desse modo, amarram-se os momentos discursivos briefing e brainstorm e a sua conjugação no intradiscurso constitui o discurso publicitário, dando vida às ideias criativas tidas no brainstorm, desde que adequadas ao briefing.

Em Análise do Discurso os pré-construídos provenientes do briefing e do interdiscurso se sintagmatizam no fio do discurso, na formulação do discurso publicitário. O pré-construído fornece os objetos de que o sujeito se apropria para fazer deles os objetos de seu discurso. No dizer que ilusoriamente supõe ser seu, incorporamse pré-construídos das áreas de marketing e planejamento, expostos no briefing, e aderese a pré-construídos do senso comum, como as referências dos criativos oriundas do interdiscurso. Ambos são considerados pré-construídos e desta forma irrompem no brainstorm. Esses discursos-outros, diferentes entre si e pertencentes a formações discursivas distintas, são agrupados na agência de propaganda em torno de um saber, formando o discurso publicitário.

Aferimos que os criativos são permeados por discursos-outros que vêm via memória discursiva, materializam-se como pré-construídos e são dispostos no intradiscurso. Esses pré-construídos são produzidos no exterior da FD e incorporados por ela em função das posições ideológicas.

Julgamos importante destacar e distinguir os dois tipos de pré-construído com os quais estamos operando e que se atravessam no processo criativo do discurso publicitário: aquele que vem do primeiro momento discursivo (briefing) e, por atacado, do anunciante, é distinto daquele outro que vem do interdiscurso para dar materialidade ao primeiro.

Em síntese, o anunciante fornece os objetos - que se formam como préconstruídos - do discurso publicitário (produto/serviço, prazo, verba, público-alvo) no momento discursivo um (briefing), e o interdiscurso fornece os demais pré-construídos. Ambos são produzidos no exterior e interiorizados durante o momento discursivo dois (brainstorm). Esclarecemos, ainda, que este segundo é determinado pelo primeiro tipo de pré-construído, isto é, o briefing, enquanto pré-construído, determina o interdiscurso, pois os pré-construídos que não vem do momento discursivo anterior (o briefing) remetem, necessariamente, aos pré-construídos deste primeiro momento discursivo, haja vista que só são mobilizados graças aos sentidos instalados pelo momento discursivo anterior. Em função de penderem para o mesmo sentido, muito embora possam ser saberes de ordens distantes, os pré-construídos mobilizados do interdiscurso dependem dos pré-construídos do briefing. Há uma relação de dependência entre o (sentido) que vem depois com o (sentido) que veio antes, para que haja um retorno a um mesmo espaço dizível.

Dito de maneira mais simples, os pré-construídos vindos do interdiscurso e que se atravessam no segundo momento discursivo somente são mobilizados graças aos sentidos empregados pelo momento discursivo anterior. Nesse ponto, é importante 
reavivarmos que o processo criativo do discurso publicitário não é um processo "mágico", sem explicação. Tudo será resultado da fase anterior, uma vez que os préconstruídos que estão por trás do dizer estão determinados no briefing e delimitam aqueles procedentes do interdiscurso, dos quais os criativos se apropriam durante o brainstorm.

Atentamos para o caráter essencial da mobilização da noção de pré-construído para a compreensão do funcionamento da heterogeneidade no processo criativo do discurso publicitário. Atestamos que o pré-construído irrompe exatamente dos dois modos de desdobramento do "outro": aquele que é proveniente do Outro (interdiscurso) e aquele que vem do outro (interlocutor). Este último, o outro do interlocutor, procede do anunciante e está marcado no briefing. O primeiro, por sua vez, é o Outro do interdiscurso.

Compete ao criativo publicitário organizar estas duas modalidades de préconstruído no fio do discurso. Tal estruturação se materializa quando ambos préconstruídos são articulados. Isso acontece durante o brainstorm, do qual o anunciante não participa diretamente.

Como contribuição teórica, registramos o fato de, no processo de criação publicitária, o sujeito operar com pré-construídos distintos e, logicamente, de ordens discursivas distintas, transportando consigo dizeres, saberes, enunciados e sentidos. Ao discutir sobre essa questão cumprimos com o centro da nossa proposição: inquirir a presença constitutiva do outro no interior do processo criativo do discurso publicitário.

Os sentidos vêm demarcados da exterioridade, previamente estabelecidos no briefing, enquanto expressão ideológica do anunciante. Assim, constatamos que os sentidos são constituídos em referência à relação com a exterioridade. $\mathrm{O}$ mesmo vale para o brainstorm. As ideias criativas que emergem durante este segundo momento discursivo são, igualmente, dependentes do que vem de fora, do que é exterior - o préconstruído proveniente do interdiscurso -, e, mais do que isso, têm conexão direta com o primeiro momento discursivo - o briefing -, o pré-construído que vem do anunciante.

Ambos, briefing e brainstorm, são presenças ausentes no anúncio publicitário, mas que no processo criativo têm, no mínimo, pesos equivalentes. Cada qual é atravessado por pré-construídos que, uma vez unidos, configuram o discurso publicitário. Contudo, a partir da máxima de que cada nível se apresenta como um préconstruído em relação ao subsequente, que no nível seguinte se torna um construído, podemos sustentar que o briefing é o pré-construído do brainstorm, demonstrando não apenas que o briefing norteia o brainstorm, mas também de que maneira desempenha tal condição.

\section{BIBLIOGRAFIA}

BERTOMEU, João Vicente Cegato. Criação na propaganda impressa. São Paulo: Futura, 2002.

HENRY, Paul. Os fundamentos teóricos da "Análise Automática do Discurso" de Michel Pêcheux. Tradução de Bethania Mariani. In: GADET, Françoise; HAK, Tony. (orgs.). Por uma análise automática do discurso: uma introdução à obra de Michel Pêcheux. 2 ed. Campinas: Unicamp, 1993, p. 13-38. Tradução do original de 1969.

ORLANDI, Eni. Análise de Discurso: princípios e procedimentos. 3. ed. Campinas: Pontes, 2001. 
PÊCHEUX, Michel. Semântica e Discurso: uma crítica à afirmação do óbvio. Tradução de Eni Orlandi [et al.] 3. ed. Campinas: Unicamp, 1997. Tradução de: Les vérités de La Palice, 1975. 